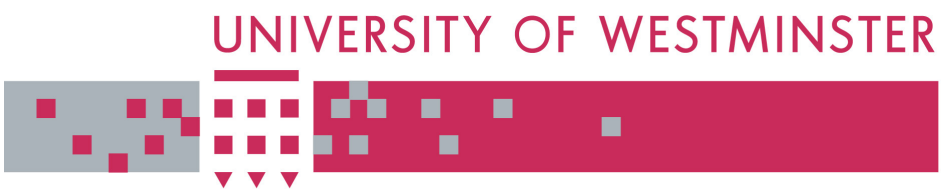

\title{
WestminsterResearch
}

http://www.wmin.ac.uk/westminsterresearch

\section{Prevalence of dieting, overweight, body image satisfaction and associated psychological problems in adolescent boys.}

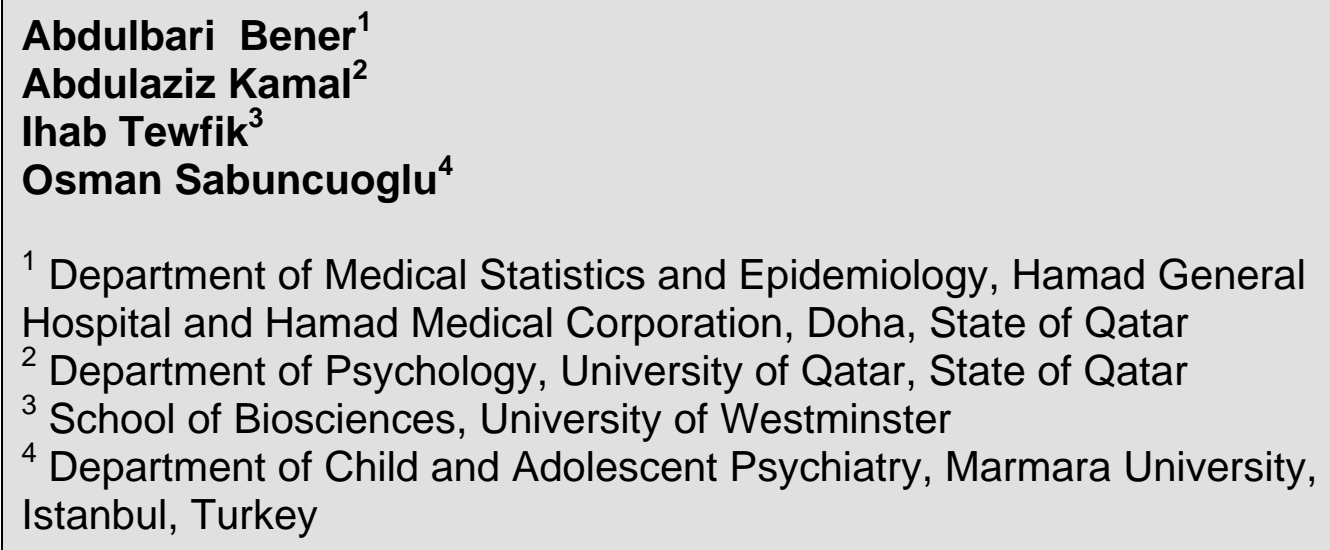

This is an electronic version of an article published in Nutrition \& Food Science, 36 (5). pp. 395-304, 2006. The definitive version is available online on the journal homepage:

http://www.emeraldinsight.com/info/journals/nfs/nfs.jsp

The WestminsterResearch online digital archive at the University of Westminster aims to make the research output of the University available to a wider audience. Copyright and Moral Rights remain with the authors and/or copyright owners. Users are permitted to download and/or print one copy for non-commercial private study or research. Further distribution and any use of material from within this archive for profit-making enterprises or for commercial gain is strictly forbidden.

Whilst further distribution of specific materials from within this archive is forbidden, you may freely distribute the URL of WestminsterResearch.

(http://www.wmin.ac.uk/westminsterresearch). 
PREVALENCE OF DIETING, OVERWEIGHT, BODY IMAGE SATISFACTION

AND ASSOCIATED PSYCHOLOGICAL PROBLEMS

IN ADOLESCENT BOYS

\author{
Abdulbari Bener ${ }^{1}$, Abdulaziz Kamal ${ }^{2}$, Ihab Tewfik $^{3}$ \\ ${ }^{1}$ Department of Medical Statistics \& Epidemiology, Hamad General Hospital and \\ Hamad Medical Corporation, Doha, State of Qatar \\ 2 Department of Psychology, University of Qatar, State of Qatar \\ ${ }^{3}$ School of Biosciences, University of Westminster, London, United Kingdom
}

Key words: Adolescent. Eating habits. Dieting frequency. Obesity. Body image. Psychological problems. State of Qatar

Running title: Eating habits, dieting and psychological problems

\title{
* Correspondence to :
}

Prof. Abdulbari Bener

Advisor to WHO, Consultant \& Head,

Dept. of Epidemiology and Medical Statistics

Hamad Medical Corporation

University of Qatar

PO Box 3050,

Doha -State of Qatar

Office Tel: + 974- 4393765

Office Tel: + 974- 4393766

Fax:+ 974-439 3769

e-mail:abener@hmc.org.qa

e-mail:abaribener@hotmail.com 


\begin{abstract}
Background: Dissatisfaction with body weight and the use of unhealthy weight reduction practices has been reported among adolescents. It is important to conduct rigorous studies using large representative samples of adolescents to assess accurately the dieting frequency, overweight and eating disorders and attitudes.

Objective: The aim of the present study was to examine the severity of dieting and it's association with obesity, body satisfaction and psychological problems in adolescent boys.

Subjects: A representative sample of 800 boys in the age group of (14-19) years were approached during the period from October to December, 2004 and 593 boys gave consent to participate in this study, thus giving a response rate of $74.1 \%$.

Methods: Self-reports were obtained from 593 teenage boys using the Adolescent Dieting Scale (ADS), and the Self-Reporting Questionnaire (SRQ-20) for psychopathology.

Results: Of the studied subjects, $33.1 \%$ were overweight, $10.1 \%$ were extreme dieters and $37.4 \%$ were intermediate dieters. Among the dieters, 34\% were overweight. Dieting was more likely in subjects who practiced exercise and who were perceived by peers or themselves as overweight. The extreme dieters experienced psychological problems than the intermediate dieters and non dieters. Extreme dieters reported sleeping problems (58.3\%), tired all the time $(53.3 \%)$ and felt like crying more than usual (50\%). Television was the main source of information on diet (61.7\%).

Conclusion: The present study findings provide a strong evidence for the association between frequent dieting and overweight, body image dissatisfaction and psychological problems.
\end{abstract}




\section{Introduction}

Adolescence is a time when social demands influence the individual and

when "others" perceptions become very significant to the individual adolescent (Hill 1989). Capacity and competence in adolescent boys are complex issues, because adolescents have a tendency to make treatment decisions by themselves (Tan and Fegert 2004). Although dieting among boys are less common when compared to girls, some studies have shown the prevalence of eating disorders among boys cannot be taken too lightly (Braun et al. 1999). In complying with the demands of being socially attractive, dieting as a method of weight control has been a common behaviour particularly in Western culture and within particular groups such as adolescents (Swadi et al. 2000). While the definition of "dieting" includes weight-reduction efforts generally considered to be healthy (e.g., increased fruit and vegetable intake and decreased fat and sugar intake), many individuals also consider "dieting" to include unhealthy weightcontrol behaviours such as fasting, skipping meals, and eliminating food groups (Ackard et al. 2002, Brownell and Rodin 1994).

While dieting may be viewed as a useful exercise in body weight control, the occurrence of psychiatric symptoms in association with dieting seems to be an indication that dieting is not necessarily a healthy method of weight control, at least in some to support this view as recently highlighted by Patton (Patton et al. 1997) who found that psychiatric morbidity was clearly associated with extreme dieters reported high levels of depression and anxiety.

There are issues of concern over the practice of dieting among boys. First, many of the adolescent boys who dieted are of normal weight for their height, yet they use unhealthy weight-control behaviours such as fasting and use appetite suppressants, rather than healthier weight-loss practices such as reducing intake of fat and sweets and increasing physical activity (Ackard et al. 2002). Usually, adolescents are using unhealthy weight-control measures (Neumark-Sztainer 1999). 
While dieting efforts among average weight or underweight individuals are most often considered negative, dieting efforts among overweight individuals have been viewed more positively (Ackard et al. 2002). For example, Wing and Jeffery (Wing and Jeffery 1999) found that among overweight individuals, modest weight reduction (10-15\% of individual body weight) achieved by the combination of calorie reduction and exercise implementation were associated with positive changes in cardiovascular risk factors. Despite a large body of literature on emotional and behavioural factors associated with dieting, we are unaware of any studies that have looked at these associations independent of body mass index (BMI).

Dieting as part of an eating disorder has been well documented and accepted in Western culture, but it was only recently that eating disorders began to be viewed as cross-cultural phenomena with reports of clinical eating disorders in the Arab World (Hill 1989, Swadi et al. 2000).

To our knowledge, no studies reported the prevalence of obesity or dieting behaviour among adolescent boys neither in Qatar nor in the region. The aim of the present study was to examine the severity of dieting and its association with obesity, body image satisfaction, and psychological problems in adolescent boys in the State of Qatar.

\section{Methods}

Qatar, independent state occupying the Qatar Peninsula, jutting into the Persian Gulf from the eastern coast of the Arabian Peninsula. On its southern side it is bordered by Saudi Arabia. Qatar has an area of 11,493 Sq. Km. The land is stony and largely barren. An extremely hot, arid climate prevails. Humidity is high during the summer, but the annual rainfall is scarce. The population of Qatar is 724,125 (Annual Health Report 2003) and 30\% of the total population constitute Qatari nationals.

A representative sample of 800 adolescent boys aged 14-19 years was included in this study. The study was conducted from October to December 2004. The population were derived from secondary and high schools in Qatar. A 
multi-stage stratified sampling design was developed. In order to secure a representative sample of the study population, the sampling plan was stratified with proportional allocation according to stratum size. The sample size was determined with the a priori knowledge that the prevalence rate of dieting in the State of Qatar is more or less similar to UAE and Western countries; or that it may be affected by parity, heredity, climate and socio-demographic and environmental factors. Allowing an error of $2.5 \%$ and level of significance (Type-1 error) of $1 \%$, it was believed that a sample size of 800 is adequate to achieve a high degree of precision in estimating the true prevalence rate of dieting in the general population. Schools were then selected according to geographical location. Of the schools selected, half of the classes were chosen (e.g. $5 \mathrm{~A}, 5 \mathrm{C}$, $5 \mathrm{E} . .6 \mathrm{~A}, 6 \mathrm{C}, 6 \mathrm{E}$ etc.). In those classes, half of the students were chosen on the basis of alternate names according to the class registration list. A total of 800 boys were approached and 593 expressed their consent to participate in this study. Two hundred and seven boys were excluded from the study due to incomplete questionnaire or did not give their consent or did not want to respond to the questionnaire due to lack of time.

\section{Instruments}

Self reports were obtained by using Adolescent Dieting Scale (ADS) (Patton et al. 1997) and Self Reporting Questionnaire (SRQ-20) (El-Rufaie and Absood 1994) for psychopathology. Questionnaire including the general demographic variables and dieting information was filled out by the Research Assistants. The anthropometrics measures of adolescent boys were measured and collected by qualified nurses.

1. The Adolescent Dieting Scale (ADS) (Patton et al. 1997). The Adolescent's Dieting Scale (ADS) consists of 8 items and for each question; there are 4 possible answers "seldom or never, sometimes, almost, always". They attracted a score of $0,1,2,3$ respectively. The ADS is based on a refinement of a number of other scales for measuring dietary restraint. The authors identified 
behaviours typical of dieting but did not include the extreme weight control strategies that are characteristics of clinical eating disorders. They identified nine behaviours, which covered three broad dieting strategies (calorie counting, reducing food quantity and meal skipping). The unidimensionality of the ADS was assessed by using a principal component analysis which showed that, for the nine item scales, there were two main components, one with an Eigen value of 5.4 and another with a much smaller Eigen value of 1.2. However, they found that one of the items "skipping breakfast" has a low item correlation and therefore carried out a separate analysis without that item. The alpha co-efficient for the eight items scale was 0.83 and it had two principal components with an Eigen value of 3.5 and the other component had a Eigen value of 1.0. On that basis, they considered the 8-item ADS a suitable scale for measuring dieting in a nonclinical population. Three bands of dieting in a non-clinical population. Three bands of dieting, minimal (total score 1-6, intermediate (total score 7-14) and extreme (total score more than 15) were identified using data obtained from their study.

Because of the ease of administration, the feasibility of quantification of dieting and understand ability and acceptability of this questionnaire, we decided to use it in our survey. Moreover, it seems to be culture free since it inquires about specific behaviours rather than concepts, which may be influenced by cultural factors. We therefore did a translation into Arabic with back- translation by a non-clinician who was fluent in both Arabic and English. We piloted the questionnaire on a small number of adolescents who reported that the questionnaire was understandable and easy to answer. There were minimal changes in the wording following the piloting process. For the above reasons, we did not feel that a full validation study of the ADS in this culture was not necessary and was not carried out.

The Arabic Version of the Self Reporting Questionnaire (SRQ) (ElRufaie and Absood 1994). This is a screening instrument for identifying potential psychiatric cases in community settings and is not designed for diagnostic 
purposes. The original version (Harding et al. 1980) consists of 20 items designed to detect non-psychotic symptoms. Each item would attract a score of I for a 'yes' response and 0 for a 'no' response. It has been found to have a fairly good sensitivity and specificity and has been successfully used in adolescent populations (Feijo et al. 1997). El Rufaie \& Absood (El Rufaie and Absood 1994) validated the SRQ- 20 in a primary care sample in the United Arab Emirates and found it to be a valid instrument for detecting minor psychiatric morbidity.

BMI was calculated as the weight in kilograms (1 $\mathrm{kg}$ subtracted to allow for clothing) divided by height squared in meters. Subjects were classified into 3 categories: acceptable weight $\left(\mathrm{BMl}<25 \mathrm{~kg} / \mathrm{m}^{2}\right.$ ); overweight (BMI 25-29.9 $\left.\mathrm{kg} / \mathrm{m}^{2}\right)$; and obese (BMI 30+ kg/m²) (Garner 1993).

\section{Statistical Methods and Analysis}

The Statistical Package for Social Sciences (SPSS) (Norusis 1997) was used for statistical analysis. Data were expressed as mean and standard deviation (SD) unless otherwise stated. Student-t test was used to ascertain the significance of differences between mean values of two continuous variables. Chi-square analysis was performed to test for differences in proportions of categorical variables between two or more groups. In $2 \times 2$ tables, the fisher's exact text (two tailed) replaced the chi-square test if the assumptions underlying chi-square violated, namely in case of small sample size and where the expected frequency is less than 5 in any of the cells. One-way analysis of variance (ANOVA) was employed for comparison of several group means and to determine the presence of significant differences between group means of continuous variables. The level $p<0.05$ was considered as the cut-off value for significance.

\section{Results}

A total of 593 of 800 enrolled school boys participated in this study,thus giving a response rate of $74.1 \%$. 
Table 1 shows the socio-demographic characteristics of the studied subjects. The mean BMI for the studied population was 23.2 (SD 3.9) (with range of 15.6 to 34.0). Of the total respondent population, BMI calculation showed that $196(33.1 \%)$ fell above the $25 \mathrm{Kg} / \mathrm{M}^{2}$. But, among the dieters, 34\% were overweight.

Table 2 shows the Adolescent Dieting Score and BMI by age group. Only a small minority of the adolescent boys were non-dieters (11.8\%). Almost $90 \%$ were dieting mostly on a minimal or moderate basis. However, $10.1 \%$ were extreme dieters. The prevalence of dieting did not show great variations in the two age groups of 14-16 years and 17-19.

Table 3 shows the comparison of dieting severity by Adolescent Dieting Scale. Among the overweight boys, 49\% were dieters. Extreme dieting was higher among the subjects whose family members practiced dieting, however no significant difference was found. Dieting was most likely to be practiced among subjects who had a family history of arthritis $(P=0.008)$ and heart disease $(P<0.001)$. Dieting was clearly associated with exercise showing that those who diet more often also practiced exercise regularly $(P=0.002)$. Self perception and peers perception of body weight also contributed heavily to the boys ADS score $(P<0.001)$ in both cases.

Table 4 shows the association between the dieting behaviour and psychological factors in studied adolescent boys. Television and Magazines were the main sources of information for the extreme dieters on dieting and have shown a significant association. About $23.3 \%$ of extreme dieters got their information on dieting from school friends compared to $12.5 \%$ of non dieters and $18.9 \%$ of intermediate dieters $(P=0.037)$. Television was the main source of information on diet for all subjects and again the extreme dieters were more influenced by the information through television (61.7\%). The self-reported questionnaires revealed that poor appetite (45\%) was more common among the extreme dieters. The other significant psychological problems among the extreme dieters were that sleeping problems (58.3\%) and feeling tired all the time $(53.3 \%)$, crying more than usual $(50 \%)$. 


\section{Discussion}

The rate of overweight among children continues to increase in every society. Overweight and distorted body perception can both lead to serious physical and psychological problems (Strauss 1999). Specific risk factors of eating disorders are body dissatisfaction, low self esteem, high need for social approval and history of physical abuse among adolescents (Garner 1993). It is interesting to point out that their actions are focused on diet without paying much attention to other aspects of life style including physical activity and even psychosocial problems.

There are very few studies on dieting and eating behaviour conducted in other Arab countries. Two relevant studies have been recently carried out, but their main focus was on obesity. Both studies indicated that a significant proportion of males (adults and adolescents) were overweight. First, Musaiger (Musaiger et al. 2003) found that $17.1 \%$ of male students were overweight and $8.4 \%$ were grossly obese. More recently, a cross-sectional study (Bener and Kamal) involving a sample of 8566 secondary and high school students boys aged 14 to 19 years found that $11.9 \%$ of boys were at a risk of being overweight. The rate reported in our study was higher than these studies that $33.1 \%$ of the adolescent boys were overweight. But, the overweight rate of Qatari adolescent boys were very similar to the rate found in a study of Fonseca (Fonseca et al 2002) that the proportion of overweight individuals among boys (BMI greater than $90^{\text {th }}$ percentile of the Brazelian population) was $23.9 \%$.

Of the studied adolescent boys in the current study, 37.4\% were intermediate dieters and $10.1 \%$ were extreme dieters which is quite higher than the rate found in an Australian study (Patton et al. 1997) that $12 \%$ of boys and $38 \%$ of girls were categorized as "intermediate dieters" and $1 \%$ of boys and $7 \%$ of girls were extreme dieters". Despite differences in methodology, several Western studies indicated that dieting (of varying severity) is a common behaviour even among young people of normal weight range. Wooley and 
Wooley (Wooley and Wooley 1984) estimated that $72 \%$ of adolescents and young adults were dieting.

A research (Xie et al. 2003) done by the Institute for Health Promotion and Disease Prevention in California documented that perceived overweight boys and girls were more likely to experience anxiety and depression than perceived normal and underweight subjects. In our study, half of the extreme dieters had significant psychological problems like crying more than usual (50\%), sleeping problems (58.3\%) and feeling tired all the time (53.3\%).

Environmental influences particularly peer group's perceptions and attitudes, role models and learned behaviour seem to be influential in this respect. The mass medical are believed to encourage girls to form unrealistically think body ideals (Field et al. 1999), but their impact on boys has not been investigated earlier. A study from Portugal (Fonseca et al. 1998) also reported that among boys the main factors for dieting were parental supervision and body mass index. Also a report from Latin America (McArthur 2001) found that the adolescents are very interested in learning more about obesity and weight loss methods.

A study on Body weight perception among Bahraini adolescents (AI Sendi 2004) revealed a significant discrepancy between adolescents' perception of body weight and actual BMI. There was a tendency for teenagers to underestimate their weight status, which was especially noteworthy among the overweight and obese. One third of the adolescent boys thought that their parents and their peers, respectively, could consider them to be overweight or obese. Data revealed in our study that self perception and peers perception of body weight also contributed heavily to the boys ADS score $(P<0.001)$ in dieters. But, Steen (Steen et al. 1996 ) reported in their study that the obese boys perceived themselves to be less overweight and happier with their looks than obese girls.

The use of problematic weight loss tactics were significantly higher among students who are involved in substance misuse reported by several studies (Garry et al. 2003, Durant et al. 1999). We have not covered these factors in our 
study. Weight concerns develops among girls in all weight spectrum but among the boys it is strongly related to body mass index (Field et al. 2001). On the contrary, our results showed that there is no association of dieting with body mass index. The only factors which contribute to start dieting among Qatari boys is self perception and peer's perception of their own figure.

\section{Conclusion}

The present study findings revealed a strong evidence for the association between frequent dieting and eating disorders, body image dissatisfaction and psychological problems in adolescent boys in Qatar. Half of the overweight boys were dieters. Extreme dieters were under stress like they felt like crying more than usual, could not sleep well and felt tired all the time. Special attention needs to be directed toward teenagers for educating them about a healthy weight, body image, nutrition and exercises using culturally appropriate materials.

\section{References}

Ackard DM, Croll JK, Kearney-Cooke A. (2002) Dieting frequency among college females: association with disordered eating, body image, and related psychological problems. Journal of Psychosomatic Research, 52: 129-136.

Al Sendi AM, shetty P, Musaiger AO. (2004) Body weight perception among Bahraini Adolescents child care health Dev, 30(4), 369-76.

Annual Health Report for the year 2003, Hamad Medical Corporation \& Ministry of Public Health.

Bener A and Kamal A. The Growth pattern of Qatari School Children aged 6-18 years. Submitted to Journal of Health, Population and Nutrition.

Braun DL, Sunday SR, Huang A, Halmi KA. (1999) More males seek treatment for eating disorders. Int J Eat Disord , 25:415-424 
Brownell KD, Rodin J. (1994) The dieting maelstrom: is it possible and advisable to lose weight? Am Psychol, 49:781-91.

DuRant RH, Smith JA, Kreiter SR and Krowchuk DP. (1999) The relationship between early age of onset of initial substance use and engaging in multiple health risk behaviors among young adolescents. Archives of Pediatric and Adolescent Medicine, 153:286-291.

El-Rufaie O, \& Absood, G. (1994) Validity of the self-reporting questionnaire (SRQ-20) in primary health care in the United Arab Emirates. International Journal of Methods in Psychiatric Research 4:45-53.

Feijo, R., Saueressig, M., Salazar, C. and Chaves, M. (1997) Mental health screening by self-report questionnaire among community adolescents in southern Brazil. Journal of Adolescent Health, 20:232-237.

Field AE, Camargo CA Jr, Taylor CB, Bekey CB, Colditz GA. (1999) Relation of peers and media influences to the development of purging behaviors among preadolescent and adolescent girls. Arch Pediatr Adolesc Med. 153:11841189.

Field AE, Camargo CA Jr., Taylor B, Berkey CS, Roberts SB, Colditz GA. (2001) Peers, parent and media influences on the development of weight concerns and frequent dieting among preadolescent and adolescent girls and boys. Pediatrics, 107:54-60.

Fonseca H, Ireland M, Resnick MD. (2002) Familial correlates of Extreme weight control behavior among adults. Int J Eat Disord, 32:441-448.

Fonseca V M, Sichieri R, Da veiga GV. (1998) Factors associated with obesity among adolescents, Rev Saude Publica, 32(6):541-9.

Garner DM, Pathogenesis of anorexia nervosa. Lancet, 1993; 54;504-17.

Garry JP, Morrissey SL, (2003) Whetstone LM. Substance use and weight loss tactics among middle school youth. Int J Eat Disord, 33:55-63.

Harding TW, de Arango MV, Baltazar J, Climent CE, Ibrahim HH, Ladrido-Ignacio L, Murthy RS, Wig NN. (1980) Mental disorders in primary health care: a study of their frequency and diagnosis in four developing countries. Psychological Medicine, 10, 231-241. 
Hill P. (1989) Adolescent Psychiatry, (Churchill Livingstone, London).

McArthur L, Pena M and Holbert D. (2001) Effects of socioeconomic status on the obesity knowledge of adolescents form six Latin American cities. Int $\mathrm{J}$ Obes, 25:1262-1268.

Musaiger A O, Lloyd O L, Bener A, Al Neyadi S M. (2003) Lifestyle factors associated with obesity among male university students in the United Arab Emirates, Nutrition \& Food Science, Vol. 33 No.4, 145-147.

Neumark-Sztainer D, Sherwood NE, French SA, Jeffery RW. (1999) Weight control behaviours among adult men and women: cause for concern? Obes Res 7:179-88.

Norusis MJ. (1998) SPSS Inc SPSS/PC+ for Windows, Base System and Advanced Statistics User's Guide, Release Version \# 11, Chicago, Illinois.

Patton G, Carlin J, Shao Q et al. (1997) Adolescent dieting: Healthy Weight Control or Borderline Eating Disorder? Journal of Child Psychology and Psychiatry 38: 299-306.

Strauss R, Childhood Obesity. (1999) Curr Probl Pediatr. 29:5-29.

Steen SN, Wadden TA, foster GD, Andersen RE. (1996) Are obese adolescent boys ignoring an important health risk ?, Int J Eat Disord, 20:281-6.

Swadi H, Bener A, Al Darmaki F. (2000) Dieting among Arab girls. The Arab Journal of Psychiatry, 11: 25-35.

Tan JO, Fegert JM. (2004) Capacity and competence in child and adolescent psychiatry, Health Care Anal. 12:285-94.

Wing RR, Jeffery RW. (1995) Effect of modest weight loss on changes in cardiovascular risk factors: are there differences between men and women or between weight loss and maintenance? Int J Obes 19:67-73.

Wooley S, Wooley O (1984) Should obesity be treated at all? In Eating and its disorders. Eds A.J. Stunkard \& E.J. Stellar, Raven, New York.

Xie B, Liu C, Chou CP, Xia J, Spruijt M D, Gong J, Li Y, Wang H, Johnson CA (2003) Weight Perception and Psychological factors in Chinese adolescents, J Adolesc Health, 33:202-10. 
Table 1. Socio-demographic characteristics of the studied subjects by gender.

\begin{tabular}{|c|c|c|c|}
\hline Variables & $\begin{array}{c}\text { Dieters } \\
\mathrm{N}=282 \\
\mathrm{n}(\%)\end{array}$ & $\begin{array}{c}\text { Non Dieters } \\
\mathrm{N}=311 \\
\mathrm{n}(\%) \\
\end{array}$ & $P$ value \\
\hline \multicolumn{4}{|l|}{ Age (Years) } \\
\hline 14-16 & $119(42.2)$ & 142(45.7) & \multirow{2}{*}{ NS } \\
\hline $17-19$ & 163(57.8) & 169(54.3) & \\
\hline \multicolumn{4}{|l|}{ Body mass index $\left(\mathrm{Kg} / \mathrm{m}^{2}\right)$} \\
\hline$\leq 25$ Normal & 186(66.0) & $211(67.8)$ & \multirow{2}{*}{ NS } \\
\hline$>25$ Overweight & $96(34.0)$ & $100(32.2)$ & \\
\hline \multicolumn{4}{|l|}{ Education } \\
\hline Intermediate & $111(39.4)$ & $128(41.2)$ & \multirow{2}{*}{ NS } \\
\hline Secondary & $171(60.6)$ & $183(58.8)$ & \\
\hline \multicolumn{4}{|l|}{ Living condition } \\
\hline Excellent & $63(22.3)$ & $60(19.3)$ & \multirow{5}{*}{ NS } \\
\hline Above average & $81(28.7)$ & $82(26.4)$ & \\
\hline Average & $43(15.2)$ & $63(20.3)$ & \\
\hline Below average & $39(13.8)$ & $41(13.2)$ & \\
\hline Poor & $56(19.9)$ & $65(20.9)$ & \\
\hline \multicolumn{4}{|l|}{ No of siblings } \\
\hline$\leq 6$ & $161(57.1)$ & $180(57.9)$ & \multirow{2}{*}{ NS } \\
\hline$>6$ & $121(42.9)$ & 131(42.1) & \\
\hline
\end{tabular}

NS=Not Significant 
Table 2. Adolescent Dieting Score (ADS) and Body mass index by age group.

\begin{tabular}{lcccccc}
\hline \hline $\begin{array}{l}\text { Age } \\
\text { group }\end{array}$ & $\begin{array}{c}\text { Non } \\
\text { dieters } \\
\text { ADS=0 }\end{array}$ & $\begin{array}{c}\text { Minimal } \\
\text { dieters } \\
\text { ADS=1-6 }\end{array}$ & $\begin{array}{c}\text { Intermediate } \\
\text { dieters } \\
\text { ADS=7-14 }\end{array}$ & $\begin{array}{c}\text { Extreme } \\
\text { dieters } \\
\text { ADS=15-24 }\end{array}$ & $\begin{array}{c}\text { BMl groups }\left(\mathrm{Kg} / \mathrm{M}^{2}\right) \\
\leq 25\end{array}$ & $>25$ \\
\hline $14-16$ & $32(12.3)$ & $110(42.1)$ & $98(37.5)$ & $21(8.0)$ & $171(65.5)$ & $90(34.5)$ \\
$\begin{array}{l}\mathrm{N}=261 \\
17-19\end{array}$ & $38(11.4)$ & $131(39.5)$ & $124(37.3)$ & $39(11.7)$ & $226(68.1)$ & $106(31.9)$ \\
$\mathrm{N}=332$ & & & &
\end{tabular}


Table 3. Comparison of dieting severity by Adolescent Dieting Scale

\begin{tabular}{|c|c|c|c|c|}
\hline Variable & $\begin{array}{c}\text { Non/Minimal } \\
\text { Dieters } \\
\text { ADS }=0-6 \\
\end{array}$ & $\begin{array}{l}\text { Intermediate } \\
\text { Dieters } \\
\text { ADS }=7-14 \\
\end{array}$ & $\begin{array}{c}\text { Extreme } \\
\text { Dieters } \\
\text { ADS }=15-24 \\
\end{array}$ & $p$ value \\
\hline $\begin{array}{l}\mathrm{BMI}, \mathrm{Kg} / \mathrm{M}^{2}(\mathrm{Mean} \pm \mathrm{SD}) \\
\mathrm{BMI} \text { group, } \mathrm{Kg} / \mathrm{M}^{2}\end{array}$ & $23.1 \pm 4.0$ & $23.4 \pm 3.9$ & $22.6 \pm 3.3$ & NS \\
\hline $\begin{array}{l}\leq 25 \\
>25\end{array}$ & $\begin{array}{l}211(53.1) \\
100(51.0)\end{array}$ & $\begin{array}{l}140(35.3) \\
82(41.8)\end{array}$ & $\begin{array}{c}46(11.6) \\
14(7.1)\end{array}$ & NS \\
\hline \multicolumn{5}{|l|}{ Dieting in family } \\
\hline $\begin{array}{l}\text { Yes } \\
\text { No }\end{array}$ & $\begin{array}{l}155(49.7) \\
156(55.5)\end{array}$ & $\begin{array}{l}118(37.8) \\
104(37.0)\end{array}$ & $\begin{array}{l}39(12.5) \\
21(7.5)\end{array}$ & NS \\
\hline $\begin{array}{l}\text { Obesity in family } \\
\text { Yes } \\
\text { No }\end{array}$ & $\begin{array}{l}241(52.6) \\
70(51.9)\end{array}$ & $\begin{array}{l}165(36.0) \\
57(42.2)\end{array}$ & $\begin{array}{c}52(11.4) \\
8(5.9)\end{array}$ & NS \\
\hline $\begin{array}{l}\text { Family history of diabete } \\
\text { Yes } \\
\text { No }\end{array}$ & $\begin{array}{l}188(51.6) \\
123(53.7)\end{array}$ & $\begin{array}{l}137(37.6) \\
85(37.1)\end{array}$ & $\begin{array}{l}39(10.7) \\
21(9.2)\end{array}$ & NS \\
\hline \multicolumn{5}{|c|}{$\begin{array}{l}\text { Family history of high blood } \\
\text { pressure }\end{array}$} \\
\hline $\begin{array}{l}\text { Yes } \\
\text { No }\end{array}$ & $\begin{array}{l}169(53.1) \\
142(51.6)\end{array}$ & $\begin{array}{l}117(36.8) \\
105(38.2)\end{array}$ & $\begin{array}{l}32(10.1) \\
28(10.2)\end{array}$ & NS \\
\hline \multicolumn{5}{|l|}{ Family history of Arthritis } \\
\hline $\begin{array}{l}\text { Yes } \\
\text { No }\end{array}$ & $\begin{array}{l}75(51.7) \\
236(52.7)\end{array}$ & $\begin{array}{c}46(31.7) \\
176(39.3)\end{array}$ & $\begin{array}{l}24(16.6) \\
36(8.0)\end{array}$ & 0.008 \\
\hline \multicolumn{5}{|l|}{$\begin{array}{l}\text { Family history of mental } \\
\text { disorders }\end{array}$} \\
\hline $\begin{array}{l}\text { Yes } \\
\text { No }\end{array}$ & $\begin{array}{c}17(42.5) \\
294(53.2)\end{array}$ & $\begin{array}{c}15(37.5) \\
207(37.4)\end{array}$ & $\begin{array}{l}8(20.0) \\
52(9.4)\end{array}$ & NS \\
\hline \multicolumn{5}{|c|}{ Family history of heart diseases } \\
\hline $\begin{array}{l}\text { Yes } \\
\text { No }\end{array}$ & $\begin{array}{c}75(46.3) \\
236(54.8)\end{array}$ & $\begin{array}{l}55(34.0) \\
167(38.7)\end{array}$ & $\begin{array}{l}32(19.8) \\
28(6.5)\end{array}$ & $<0.001$ \\
\hline \multicolumn{5}{|l|}{ Dieting friends } \\
\hline $\begin{array}{l}\text { Yes } \\
\text { No }\end{array}$ & $\begin{array}{l}165(51.7) \\
146(53.3)\end{array}$ & $\begin{array}{l}121(37.9) \\
101(36.9)\end{array}$ & $\begin{array}{l}33(10.3) \\
27(9.9)\end{array}$ & NS \\
\hline \multicolumn{5}{|l|}{ Practice Exercise } \\
\hline $\begin{array}{l}\text { Yes } \\
\text { No }\end{array}$ & $\begin{array}{l}148(46.3) \\
163(59.7)\end{array}$ & $\begin{array}{l}131(40.9) \\
91(33.3)\end{array}$ & $\begin{array}{c}41(12.8) \\
19(7.0)\end{array}$ & 0.002 \\
\hline \multicolumn{5}{|l|}{ Satisfied with own body } \\
\hline $\begin{array}{l}\text { Yes } \\
\text { No }\end{array}$ & $\begin{array}{l}215(55.6) \\
96(46.6)\end{array}$ & $\begin{array}{l}135(34.9) \\
87(42.2)\end{array}$ & $\begin{array}{c}37(9.6) \\
23(11.2)\end{array}$ & NS \\
\hline \multicolumn{5}{|l|}{$\begin{array}{l}\text { Peer's perception of } \\
\text { respondent's figure }\end{array}$} \\
\hline Overweight & $67(40.4)$ & $78(47.0)$ & 21(12.7) & \\
\hline Average & $139(50.7)$ & $111(40.5)$ & $24(8.8)$ & $<0.001$ \\
\hline Underweight & $105(68.6)$ & $33(21.6)$ & $15(9.8)$ & \\
\hline \multicolumn{5}{|l|}{ Self perception of figure } \\
\hline Overweight & $107(44.4)$ & 101(41.9) & $33(13.7)$ & \\
\hline Average & $123(53.2)$ & $87(37.7)$ & $21(9.1)$ & $<0.001$ \\
\hline Underweight & $81(66.9)$ & $34(28.1)$ & $6(5.0)$ & \\
\hline SRQ (Mean $\pm S D)$ & $6.8 \pm 3.8$ & $6.6 \pm 3.7$ & $7.4 \pm 3.9$ & NS \\
\hline
\end{tabular}


Table 4.Association between dieting severity and psychological factors

\begin{tabular}{|c|c|c|c|c|}
\hline Variable & $\begin{array}{c}\text { Non/Minimal } \\
\text { Dieters } \\
\text { ADS }=0-6 \\
(n=311)\end{array}$ & $\begin{array}{c}\text { Intermediate } \\
\text { Dieters } \\
\text { ADS }=7-14 \\
(n=222)\end{array}$ & $\begin{array}{c}\text { Extreme } \\
\text { Dieters } \\
\text { ADS }=15-24 \\
(\mathrm{n}=60)\end{array}$ & $p$ value \\
\hline \multicolumn{5}{|l|}{ Source of information on dieting } \\
\hline School & $39(12.5)$ & $42(18.9)$ & $14(23.3)$ & 0.037 \\
\hline TV & $130(41.48)$ & $107(48.2)$ & $37(61.7)$ & 0.014 \\
\hline Magazine & $123(39.5)$ & $93(41.9)$ & $27(45.0)$ & NS \\
\hline Radio & $31(10.0)$ & $28(12.6)$ & $10(16.7)$ & NS \\
\hline Often has headache & 111(35.7) & $88(39.6)$ & $25(41.7)$ & NS \\
\hline Has poor appetite & $82(26.4)$ & $58(26.1)$ & $27(45.0)$ & 0.009 \\
\hline Sleeping badly & $146(46.9)$ & 84(37.8) & $35(58.3)$ & 0.009 \\
\hline Are you easily frightened & $111(35.7)$ & $81(36.5)$ & $24(40.0)$ & NS \\
\hline Sometimes hand shakes & $89(28.6)$ & $62(27.9)$ & $16(26.7)$ & NS \\
\hline Feel tensed, nervous or worried & $183(58.8)$ & $116(52.3)$ & $31(51.7)$ & NS \\
\hline Poor digestion & $67(21.5)$ & $49(22.1)$ & $22(36.7)$ & 0.035 \\
\hline Having trouble thinking clearly & $140(45.0)$ & $87(39.2)$ & $21(35.0)$ & NS \\
\hline Feeling unhappy & $101(32.5)$ & $91(41.0)$ & $18(30.0)$ & NS \\
\hline Crying more than usual & 104(33.4) & 75(33.8) & $30(50.0)$ & 0.041 \\
\hline Difficulty in enjoying daily activities & $93(29.9)$ & $77(34.7)$ & $22(36.7)$ & NS \\
\hline Difficulty in making decisions & $120(38.6)$ & $90(40.5)$ & $22(36.7)$ & NS \\
\hline Daily work is suffering & $110(35.4)$ & $81(36.5)$ & 17(28.3) & NS \\
\hline Unable to play useful part in life & $75(24.1)$ & $47(21.2)$ & $19(31.7)$ & NS \\
\hline Lost interest in things & $106(34.1)$ & $77(34.7)$ & $15(25.0)$ & Ns \\
\hline Feeling worthless person & $36(11.6)$ & $31(14.0)$ & $6(10.0)$ & NS \\
\hline Thought of losing life in mind & $78(25.1)$ & $55(24.8)$ & $20(33.3)$ & NS \\
\hline Feeling tired all the time & $156(50.2)$ & $92(41.4)$ & $32(53.3)$ & NS \\
\hline Uncomfortable feeling in stomach & $97(31.2)$ & $56(25.2)$ & $16(26.7)$ & NS \\
\hline Easily tired & $107(34.4)$ & $61(27.5)$ & $25(41.7)$ & NS \\
\hline
\end{tabular}

